\title{
Los muros plásticos del hospital mental. Una historia visual de la locura en la modernidad*
}

The plastic walls of the mental hospital.

A visual history of madness in modernity

As muros do plástico do hospital psiquiátrico.

Uma história visual de loucura na modernidade

\section{Jairo Gutiérrez Avendaño**}

Universidad Católica Luis Amigó, Colombia

Correo electrónico: jairo.gutierrezav@amigo.edu.co

Revista Corpo-grafías: Estudios críticos de y desde los cuerpos / Volumen 5 - Número 5 / enero - diciembre de 2018 /

ISSN impreso 2390-0288, ISSN digital 2590-9398 / Bogotá, D.C., Colombia / pp. 160-173.

Fecha de recepción: 31 de mayo de 2017

Fecha de aceptación: 15 de agosto de 2017

Doi: https://doi.org/10.14483/25909398.14214

Cómo citar este artículo: Avendaño, J. (2018, enero-diciembre). Los muros plásticos del hospital mental. Una historia visual de la locura en la modernidad. Revista Corpo-grafías: Estudios críticos de y desde los cuerpos, 5(5), p-p 160-173 / ISSN 2390-0288.

*Artículo de investigación.

**Doctor en Ciencias Humanas y Sociales de la Universidad Nacional de Colombia (UNAL), Magíster en Educación de la Universidad de Medellín (UdeM), Filósofo de la Universidad de Antioquia (UdeA), docente e investigador de la Universidad Católica Luis Amigó.

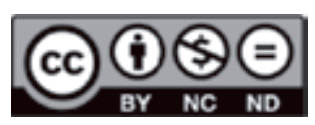




\title{
Resumen
}

El objetivo de este estudio es comprender la producción de sentido estético e histórico de la locura en Colombia, a través de la serie de murales del Hospital Mental de Antioquia, pintados por Herrera en 1982, donde se plasman conjuntos y temas relacionados con la iconografía clásica del alienismo europeo, el mito del primitivismo y degeneración de la raza, cientificidad y terapéuticas, delirios y alucinaciones, alteración nerviosa de la vida moderna y neurosis colectiva, criminalización del loco, fisionomía femenina de la locura, liberación de cadenas y ascenso del alma.

Palabras clave: locura; estética; historia; modernidad; degeneración; psicopatología de la expresión.

\begin{abstract}
The objective of this study is to understand the production of aesthetic and historical sense of madness in Colombia, through the series of murals of the Mental Hospital of Antioquia, painted by Herrera in 1982, where they reflect sets and themes related to classical iconography of european alienism, the myth of primitivism and degeneration of race, scientificity and therapeutic, delusions and hallucinations, nervous alteration of modern life and collective neurosis, criminalization of madman, feminine physiognomy of madness, liberation of chains and soul ascent.
\end{abstract}

Keywords: madness; aesthetics; history; modernity; degeneration; psychopathology of expression.

\section{Resumo:}

O objetivo deste estudo é compreender a produção de sentido estético e histórico da loucura na Colômbia, através da série de murais Hospital Mental de Antioquia, pintado por Herrera em 1982, que se reflectem conjuntos e tópicos relacionados iconografia clássica de alienismo Europeia, o mito do primitivismo e degeneração da raça, cientificidad e terapêuticos, delírios e alucinações, distúrbio nervoso da vida moderna e neurose coletiva, a criminalização de louco fisionomia, do sexo feminino de loucura, liberando correntes e aumento alma. .

Palavras-chave: loucura; estética; história; modernidade; degeneração; psicopatologia da expressão. 


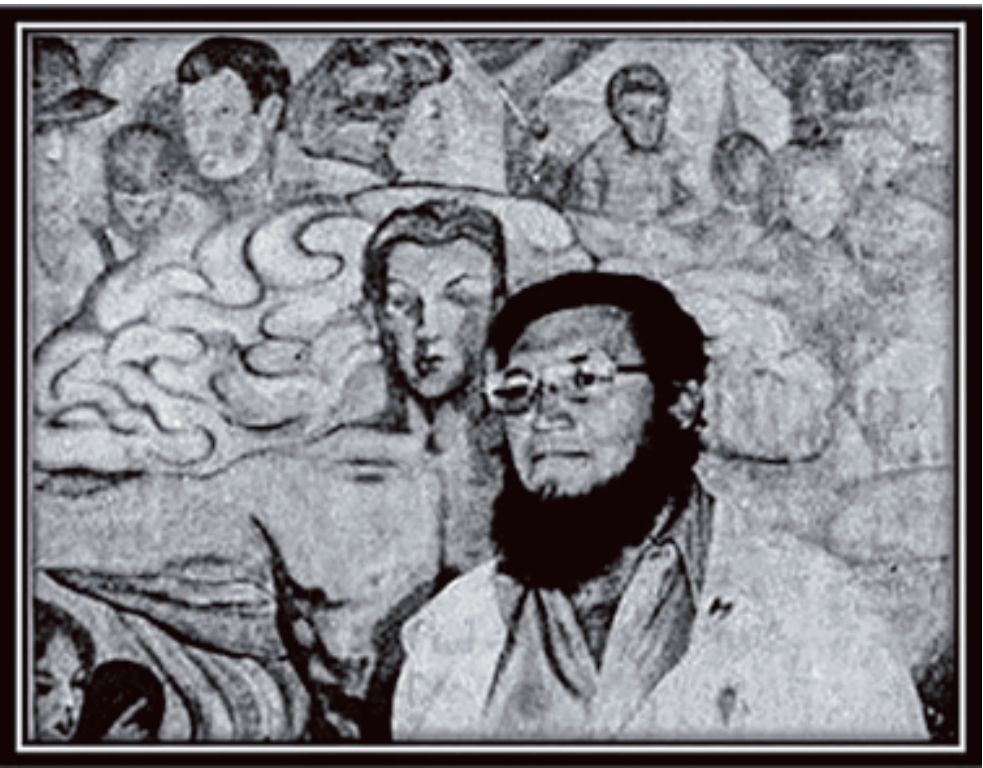

Imagen 1. "La vida: una locura que adoro. La labor de Antonio Herrera"

Fuente: Restrepo, 1978, p. 12A. Foto:

Pedronel Ospina

"Pasado y presente de la psiquiatría en Antioquia" (1982) es el título de una serie de murales coloridos de gran formato pintados en el Hospital Mental de Antioquia por el artista antioqueño Antonio Herrera Cardona ${ }^{1}$, luego de dos décadas de funcionamiento del establecimiento desde 1959. Su obra está ejecutada en acrílico y es una mezcla de impresionismo y expresionismo, que tiene como eje la figura humana y, en especial, la de la mujer (Restrepo, 1978, p. 12A).

Según el autor, en su obra incursionó en la corriente de la psicopatología de la expresión. Esta tuvo origen en el movimiento del Surrealismo de la primera mitad del siglo XX, en especial con la publicación de Jean Dubuffet titulada Prospectus aux amateurs de tout genre (1946), colección a la que llamó Art brut, compuesta por obras de marginados, delincuentes, presos, jubilados y, sobre todo dementes. Como oficialización de este llamado movimiento "artístico", se celebró en Paris, en 1950, el 1er Congrès International d'Art Psychopathologie de Vérone, en el marco del 1er Congrès Mondial de Psychiatrie, en el que se exhibieron cerca de 2000 obras realizadas por 350 pacientes (Gómez, 2005, p. 7). Desde 1963 se publicó en castellano una serie que incluía láminas analizadas por expertos titulada: Psicopatología de la expresión. Una colección iconográfica internacional. Algunos de los trabajos presentados procedían de los congresos anuales de la Société Internationale de Psychopathologie de l'Expression et d'Art thérapie, creada en 1959 en Paris (Hernández, 200, p. 2).

El mural principal del HOMO, de más de dos metros de alto y de ancho, está instalado en el costado izquierdo de la recepción, por donde se ingresa al bloque administrativo y están ubicados los módulos de información y admisión. La plástica de la obra transmite a los visitantes impresiones sobre el mito, la fantasía, la ciencia y la historia cultural de la locura. En su base, se retratan algunos precursores de la psiquiatría en Occidente, tales como Kraepelin, Freud y Charcot, al lado de los primeros médicos directores del Manicomio Departamental de Antioquia, Juan B. Londoño, Jorge Tobón y Lázaro Uribe Cálad. Estos aparecen incompletos por la instalación de un mobiliario de oficina encima del mural (Imagen 2).

1 Nació en el municipio de Pueblo Rico y vivió en Medellín gran parte de su vida, donde estudió Bellas Artes. Asistió a cursos de Filosofía del Arte y Estética en Nueva York. Fue profesor del Instituto de Bellas Artes y estuvo vinculado durante más de 15 años al área de Ergoterapia en el Hospital Mental de Antioquia (HOMO) desde 1965. En el taller del HOMO se practicaba la pintura, dibujo, repujado en cuero, cerámica, carpintería y artesanías en cabuya. Estas actividades implicaban para el paciente la "descarga constructiva", la canalización de impulsos y tendencias, la satisfacción de sentirse aceptado como un ser "productivo"; asimismo, proporcionaban seguridad y una experiencia de contacto con la realidad (Restrepo, 1978, p. 12A). 


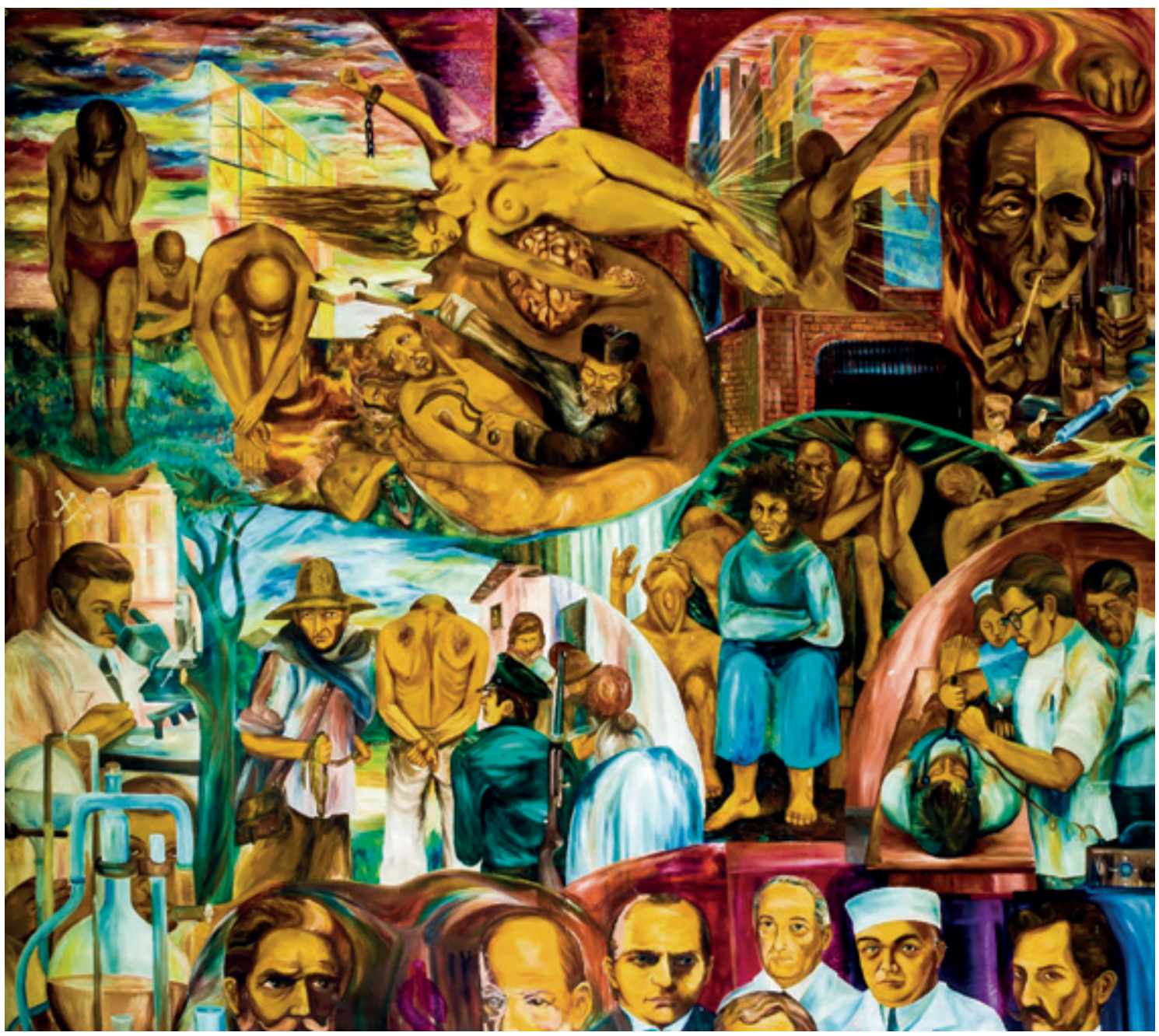

Imagen 2. Serie mural "Pasado y presente de la psiquiatría en

Antioquia". Fuente: Antonio Herrera Cardona, 1982. Hospital Mental de Antioquia. Foto: Peláez, R. y Gutiérrez, J. 2013.

En ambos extremos se destacan los avances científicos de la especialidad: en la parte inferior izquierda se observa la psicofarmacología que se empezó a administrar en los asilos de Estados Unidos y se extendió a todo el mundo durante la década del cincuenta; seguido del hombre de bata blanca en el laboratorio, que representa la neurología y psiquiatría biológica, también característica de la misma década. En el extremo derecho, se aprecia una escena de la introducción de la terapia de electrochoques, empleada en Colombia desde los años cuarenta, principalmente en casos de psicosis y depresión aguda (Gutiérrez, 2015, pp. 103-138).

Posiblemente Herrera, en la década del 80, se haya basado en la Historia de la psiquiatría en Colombia publicada por Humberto Rosselli en 1968; de hecho, los murales tienen desde el título y composición un carácter histórico, por lo tanto, los motivos y escenas corresponden a la época etiológica o búsqueda de las causas de la locura, en las que se enmarcaron las primeras cátedras de enfermedades mentales, la de Miguel Jiménez López en el Asilo de Locas de Bogotá en 1916 y la de Lázaro Uribe Cálad en el Manicomio Departamental de Antioquia en 1923 (Gutiérrez y Márquez, 2017, p. 118). 
Si se interpreta en orden descendente, desde el extremo superior izquierdo hacia la base del mismo, se aprecia el reduccionismo al complejo de colonización, que asumía el fenómeno de la locura asociado con el mito del primitivismo, al igual que la degeneración de la raza, como lo plantearon los discursos médicos y políticos de la primera mitad del siglo XX, también en relación con la inclinación al delirio, el diagnóstico de debilidad mental y con la infancia anormal.

Frente a esta actitud, en 1913, Carlos E. Putnam atribuía como causa del atraso, entre otros factores ambientales, a la pervivencia de "hábitos de la prehistórica familia indígena, con sus atavismos ancestrales" (pp. 248-259), tal cual lo refirió Jiménez López, sobre la herencia de los grupos étnicos originarios: indígena, europeo, criollo" (1920, p. 27); al igual que Uribe Cálad, quien consideraba que:

Los conquistadores de estas comarcas trajeron en sus venas la sangre de Doña Juana la Loca y de aquel gran monarca que sufrió la obsesión de la cronometría [Alfonso X, El Sabio]; aventureros nacidos en las tierras de la brujerías y de los sortilegios; tierra madre del más genial de los sistematizados reivindicadores que registran las crónicas psiquiátricas; soldados tan megalómanos como fanáticos, capaces de las más estupendas hazañas como de actos del más refinado sadismo; conquistadores que mezclaron su sangre ardiente con la del aborigen apático y melancólico, preparado ya para las degeneraciones físicas por sus bárbaros procedimientos para deformar el cráneo (1923, pp. 188-198).

El médico Emilio Robledo, en oposición a Jiménez López, no estuvo de acuerdo con la consideración de la deformación de los cráneos entre los indígenas como signo de degeneración, en tanto que el sistema de Gall no tendría aplicación en estos grupos y que las deformaciones físicas no eran muy frecuentes en los registros antropológicos y médicos del país (1920, p. 4).

En cuanto a la degeneración psíquica, el escaso aporte de los colombianos al capital intelectual de la humanidad si bien no era significativo, para Robledo - contrario a Jiménez-López - no se atribuía a una degeneración colectiva, sino a causas como la actitud pasiva y renuente instaurada por la opresión y el sometimiento durante el Descubrimiento y la Colonia (1920, p. 7).

Al lado de las tres posturas sumisas y melancólicas se levanta una ventana que hace una transición hacia el delirio y la alucinación, donde aparece un ser alado y rostros desdoblados que aluden a la mente escindida o esquizoide, junto con una criatura reptiliana verdosa. En el centro un sacerdote impone a la diestra una cruz con un oráculo por el que se vería la luz de Dios para exorcizar la posesión del mal sobre el hombre caído en sinrazón; mientras que a la izquierda empuña lo que parece un instrumento quirúrgico para la extracción de la piedra de la locura que, asimismo, representa la figura del cura del alma y del cuerpo.

No en vano, hubo casos en los que algunos pacientes confundieron al psiquiatra de turno al que llamaron "Padre". También puede aludir al delirio místico-religioso tan presente en la idiosincrasia cristiana del país. En la imagen, estas fantasías recaen en el lecho del sufrimiento psíquico del hombre abrazado por un gesto que alude al "poder del cerebro".

La siguiente secuencia, a la derecha, un resplandor marca la luz del progreso y, con el puño en alto, el hombre declara la conquista económica de la civilización y de la industrialización, proceso modernizador en oposición al atraso en que estaba sumida la nación, tema que se retoma en lo sucesivo de la serie mural. La vida anímica de la modernidad, como la definió Georg Simmel en los primeros años del siglo XX, tiene un fundamento psíquico propio del individuo urbanita: es el “acrecentamiento de la vida nerviosa, estimulado por el rápido ininterrumpido intercambio de impresiones internas y externas" (2011, pp. 375-398). 


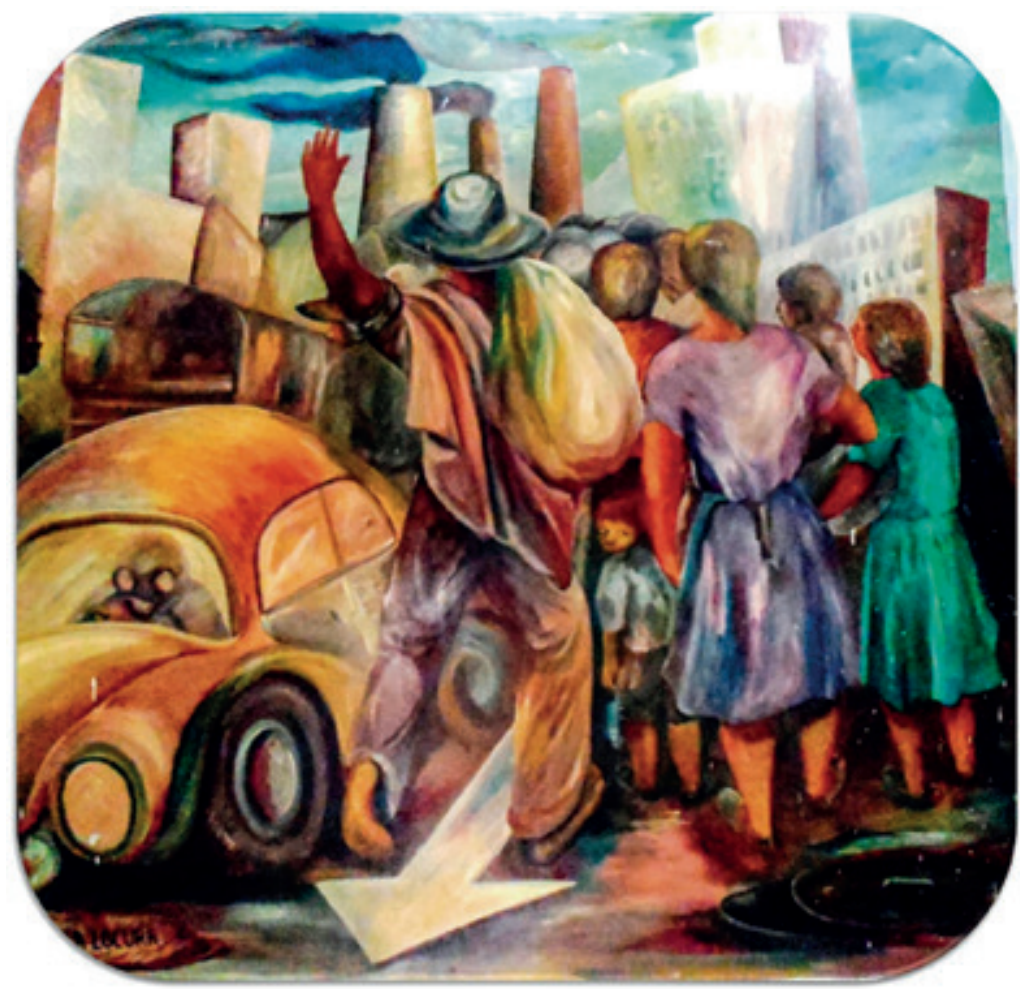

Imagen 3. Mural "Viajando a la locura"

Fuente: Antonio Herrera Cardona, 1982. Hospital Mental de Antioquia. Foto: Peláez, R. y Gutiérrez, J. 2013.
Si bien, en la primera mitad del siglo XX, se asumió que las intensidades psíquicas de la modernidad eran causantes de los desórdenes mentales, de acuerdo con Lopera, más bien se trató de un contexto histórico de "racionalización del mundo de la vida", "movilización general", "aceleración" o "inquietud" en el que se hicieron visibles desórdenes psíquicos que llamaron la atención de la opinión pública $y$, con el surgimiento de la psiquiatría desde el siglo $\mathrm{XIX}$, entraron en el dominio de la clasificación de las enfermedades mentales (2016, p. 27).

El imaginario de la aceleración del tiempo y de la vida, está relacionado con el mural "Viajando a la locura" (1982), plasmado por Herrera en el mismo hospital (Imagen 3), donde actualmente es la pared frontal de una pequeña habitación en la que se encuentra una cama hospitalaria en uso. La obra muestra la migración del campo a la ciudad, en medio del inquietante fenómeno de movilidad y medición del tiempo, con una flecha que señala en contravía a la dirección a la que se dirigen las familias en busca de oportunidades en las nuevas fábricas y talleres.

La alcantarilla destapada alude al aumento de problemas de salubridad y riesgos que afrontan los urbanitas. La mirada del niño por debajo de la muchedumbre interpela al espectador, al mirar hacia atrás expresa un momento de cambio y la incertidumbre del porvenir que exige la "lucha por la vida", expresión generalizada en los discursos y la vox populi modernos.

En efecto, en esta época, se consideró que el proceso de industrialización que produjo el éxodo del campo a la ciudad, acrecentó la "neurastenia rural", por el "cáncer de la empleomanía y funcionarismo". Según Castro, las neurastenias se debían al surmenage o fatiga mental, a la falta de éxito y complicaciones de la vida rutinaria moderna (1920, p. 14). Se destaca que, en la historia de la psiquiatría, la construcción de los primeros hospitales mentales, fueron inaugurados según retóricas y simbolismos de modernidad.

A esta epopeya de locura y civilización, en el primer mural (Imagen 2) le sigue el cuadro de consumo de sustancias psicoactivas que en los manicomios se clasificaron como toxicomanías, en las que se incluía la adicción al alcohol, mariguana, cocaína y morfina, causas exógenas de delirios y trastornos asociados a la degeneración, según factores predisponentes o hereditarios, así como determinantes o ambientales. La imagen es el típico transcurso de la decadencia de las drogas que lleva hasta la muerte, muy usada en la publicidad popular de prevención y rehabilitación. 
En el centro de la primera mitad de la Imagen 2, se observa una escena del traslado de un loco del campo a la ciudad, que ocasiona conflicto y desplazamiento para su familia por las condiciones de remisión de los pacientes al manicomio, desde municipios cercanos y de zonas remotas. Asimismo, representa la concepción de la criminalización de la locura que, según el código de policía de la época, debían ser detenidos y conducidos a la inspección de permanencia para su ingreso a los asilos de indigentes y de locos.

Según las narrativas de historias clínicas del antiguo Manicomio Departamental, se observa que en el diagnóstico de delirio, la mayoría de casos se presentaron en mujeres dedicadas a los oficios domésticos, en muchas se prestó atención a su "apariencia personal" como descripción relacionada con los síntomas, en la que entraron "desgreñadas" o desordenadas, delgadas o "enflaquecidas", desnutridas, entre otros calificativos que, según las concepciones de la imagen femenina de la locura, "en el semblante y en la gesticulación del cuerpo podemos leer una subversión de los códigos sociales y culturales que llevó al alienismo y la psiquiatría a patologizar y clasificar visualmente cualquier estado contrario al ideal normativo" (Montilla, 2016, p. 80).

Otras fisionomías, presentadas por Julia Montilla, son la de la envidiosa o "la hiena de la Salpêtrière", de la serie "Monomaníacas", pintada por Géricault; la suicida (melancolía e histeria), fotografiada por Diamond en el Surrey County Lunatic Asylum, de Springfield; la furibunda celosa y homicida, también retratada en la Salpêtrière por Duchenne de Boulongne; la liberada de las cadenas de la Salpêtrière, pintada por Robert-Fleury; la histérica, la endemoniada, la autómata o melancólica cataléptica, examinadas por Charcot y retratadas por Brouillet, Richer y Londe, respectivamente (2016, pp. 37-82).

De hecho, Georges Didi-Huberman comenta que Charcot, en un apartado de sus Leçons sur les maladies du système nerveux (1885-1887), concebía al asilo como un "museo patológico vivo", en el que la histeria devino en una invención teatral y artística, compilada en la serie de retratos de la Iconographie photographique de la Salpétriere, en la que se estimuló un deseo por ver a las histéricas, al tiempo que se creó un espectáculo clínico en el que se exhibía la puesta en escena de ataques, gritos, actitudes pasionales, crucifixiones, éxtasis y, en fin, todas las posturas del delirio (2007, pp. 7-8).

Esta representación de la locura como entidad femenina también se aprecia en otro de los murales instalados a lo largo de un pabellón (Imagen 4), en el que aparece el gesto de la locura encadenada y con camisa de fuerza; a su diestra la atiende el psiquiatra y a su izquierda la cuida una Hermana de La Caridad. Al extremo izquierdo se evoca el fenómeno de aturdimiento y confusión por la agitación de la vida en el proceso de modernización urbano-industrial, tema presente en toda la serie. Al extremo derecho, aparecen hombres despojados de sí, en harapos, hambrientos y encadenados. En la obra de Herrera se plasma la estrecha vecindad entre locura y pobreza consideradas

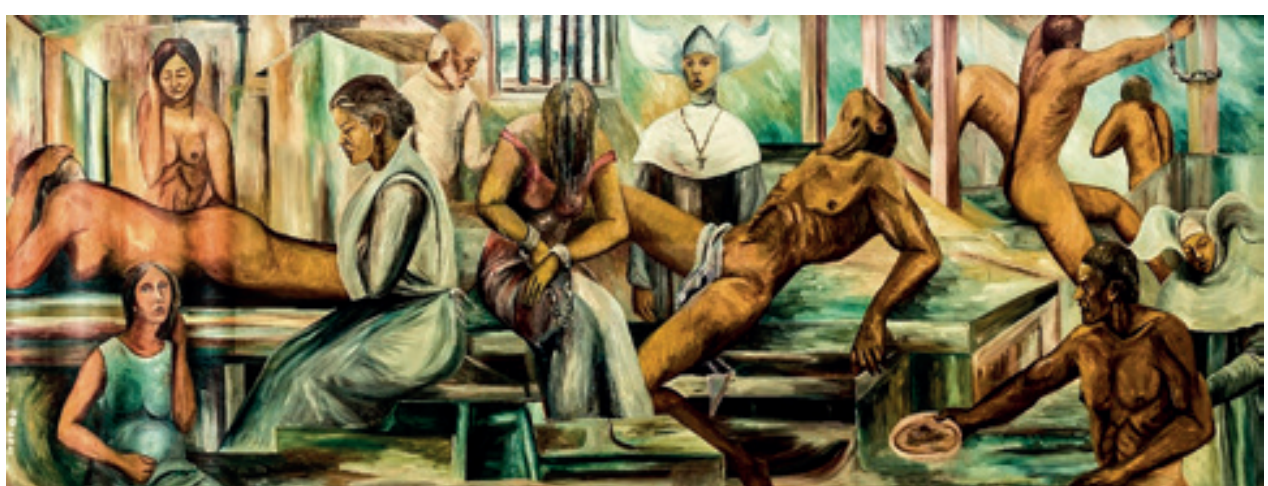

Imagen 4. Serie mural 2 "Pasado y presente de la psiquiatría en Antioquia". Fuente: Antonio Herrera Cardona, 1982. Hospital Mental de Antioquia. Foto: Peláez, R. y Gutiérrez, J. 2013. enfermedades sociales por el higienismo y la "cuestión social" de la salud, que buscaron intervenir las condiciones de vida de las clases miserables por ser consideradas factores determinantes de males degenerativos (Gutiérrez y Márquez, 2014, pp. 56-66). 
El gesto de soltar las cadenas es significativo en la historia de la psiquiatría, como se conoció por el célebre acontecimiento de Philippe Pinel, cuando en 1795 ordenó cortar los grilletes de los alienados de los asilos de Bicêtre y de La Salpêtrière, escenas pintadas por Charles Müller en 1849 y por Robert-Fleury en 1878, liberación que se replicó en todos los continentes, incluyendo a Colombia donde tardíamente continuaron encadenando a los locos en los manicomios durante la primera mitad del siglo XX.

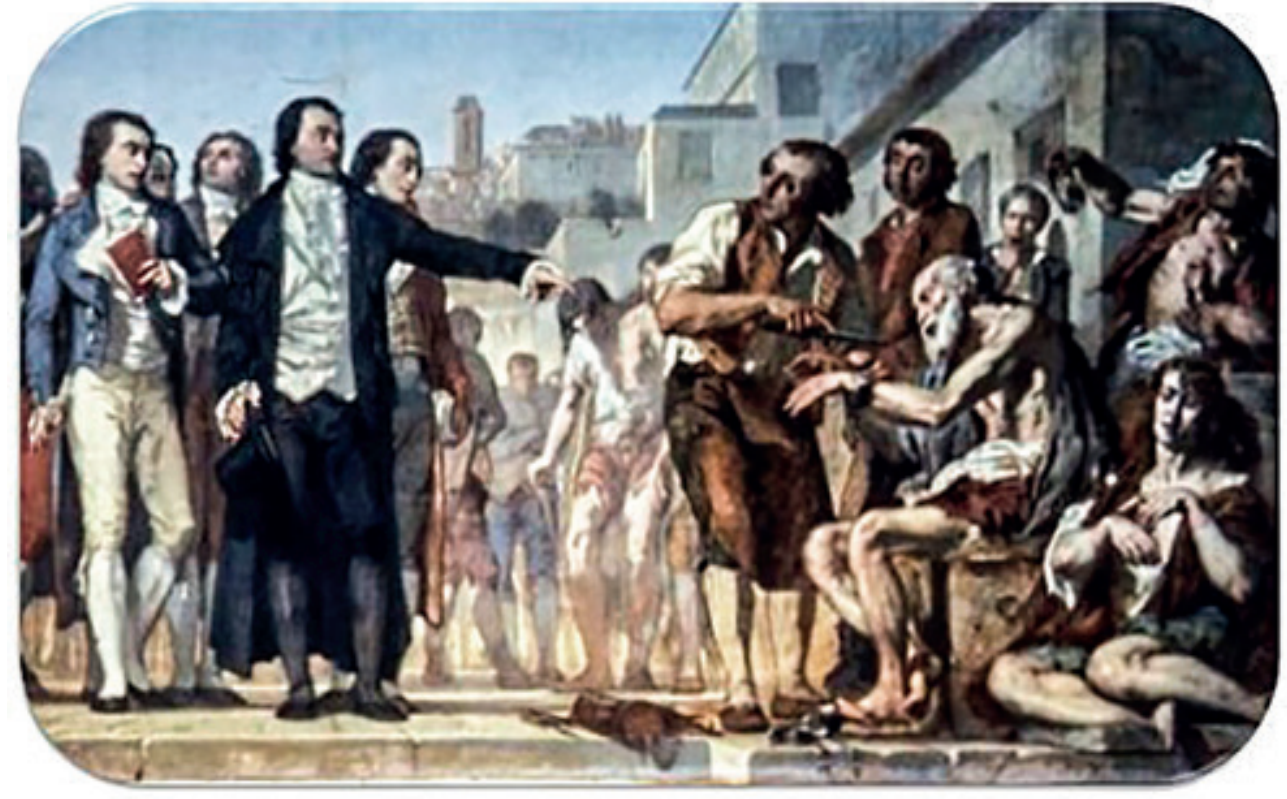

Imagen 5. Pinel fait enlever les fers aux aliénés de Bicêtre. Charles Müller, 1849

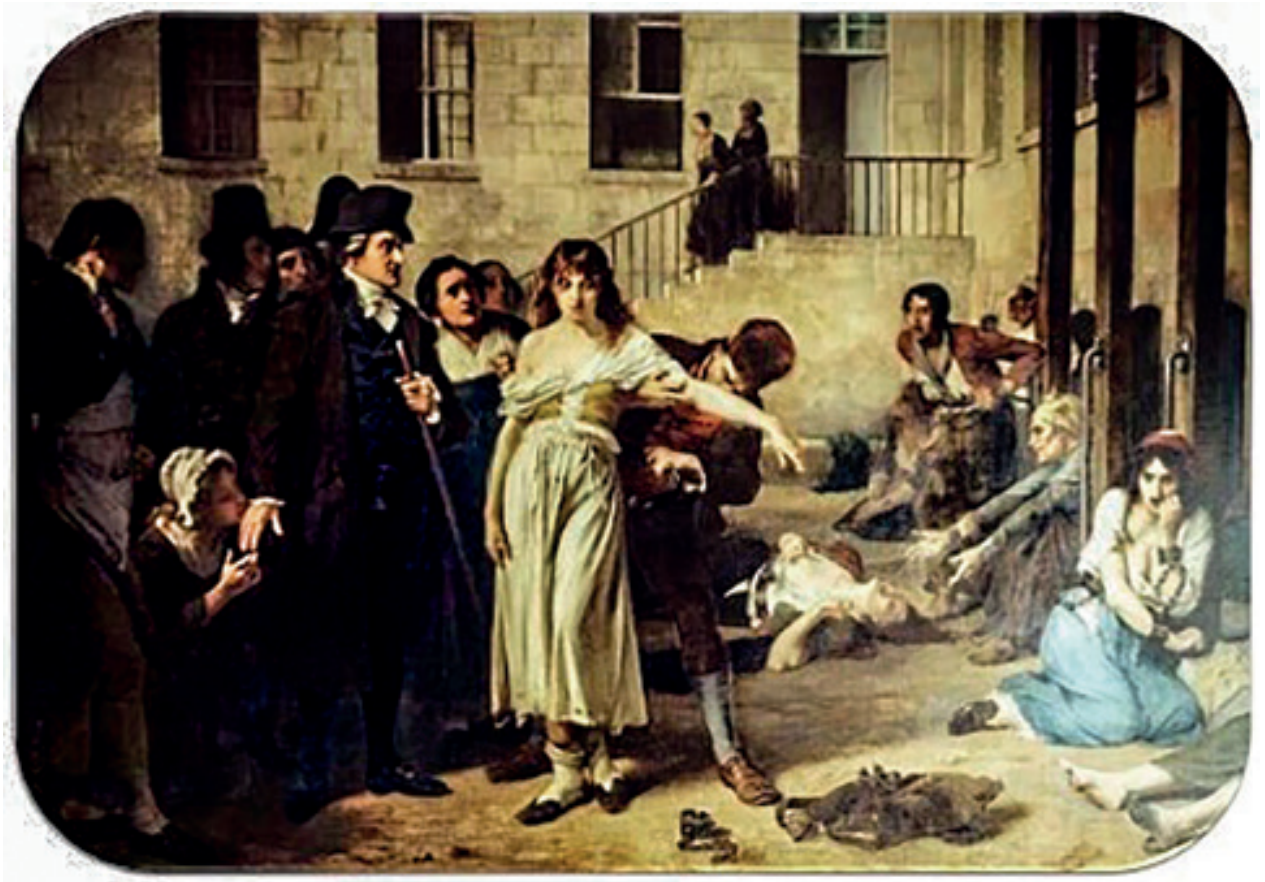

Imagen 6. Le docteur P. Pinel faisant tomber les chaînes des aliénés. Tony Robert-Fleury, 1878
En el antiguo Asilo de San Isidro en Cali, el primer acto del nuevo director, como el de Pinel en Francia, fue llevar a un herrero para cortarles las cadenas a los pacientes que estaban sujetados (Perdomo, 1996, p. 299). La Junta directiva, el mismo año manifestó que "era necesario mantener enfermos en calabozos, hacinados vergonzosamente por falta de drogas, de enfermeros $y$ enfermeras $y$ sin tratamiento. Habría que volver a las épocas medievales, a la infame Bedlam, para encontrar escenas similares a las que se presencian a diario en San Isidro" (Aljure, 1955, cit. Gutiérrez, 2015, p. 15). 
Imágenes 7 y 8. Encadenados en la Casona de San Isidro, Cali, década del 50

Fuente: Museo Casona de San Isidro, Hospital Psiquiátrico Universitario del Valle del Cauca

Imágenes 9 y 10. Cadena y grilletes del asilo.

Fuente: Museo Casona de San Isidro, Hospital Psiquiátrico Universitario del Valle del Cauca
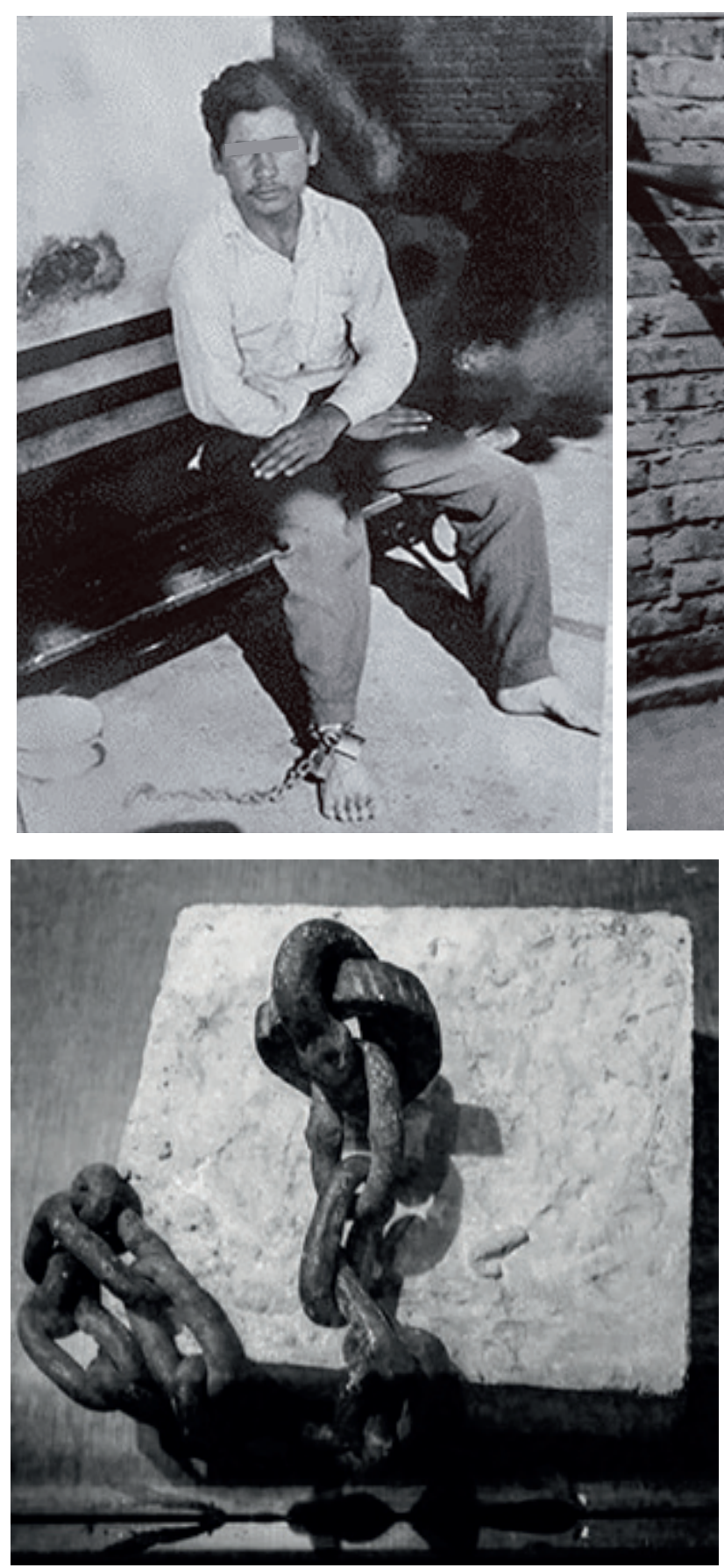

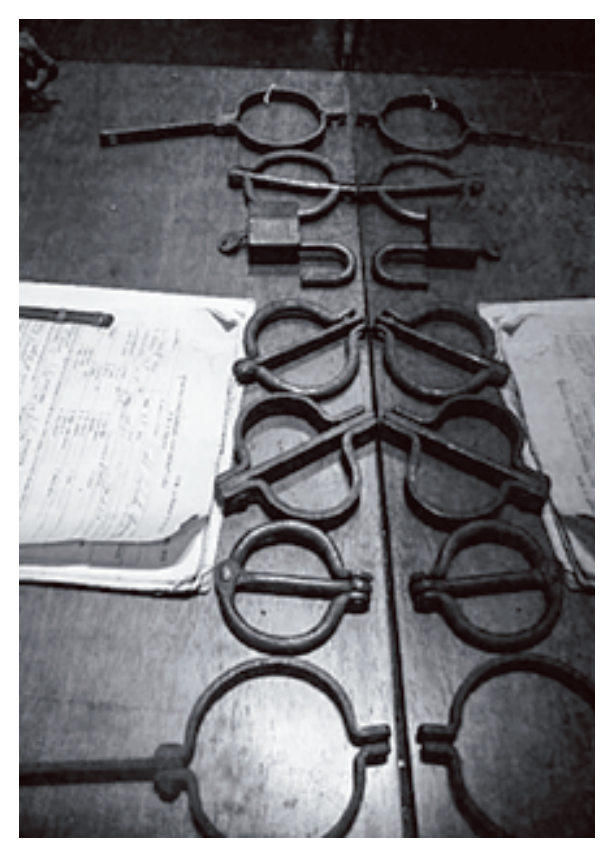

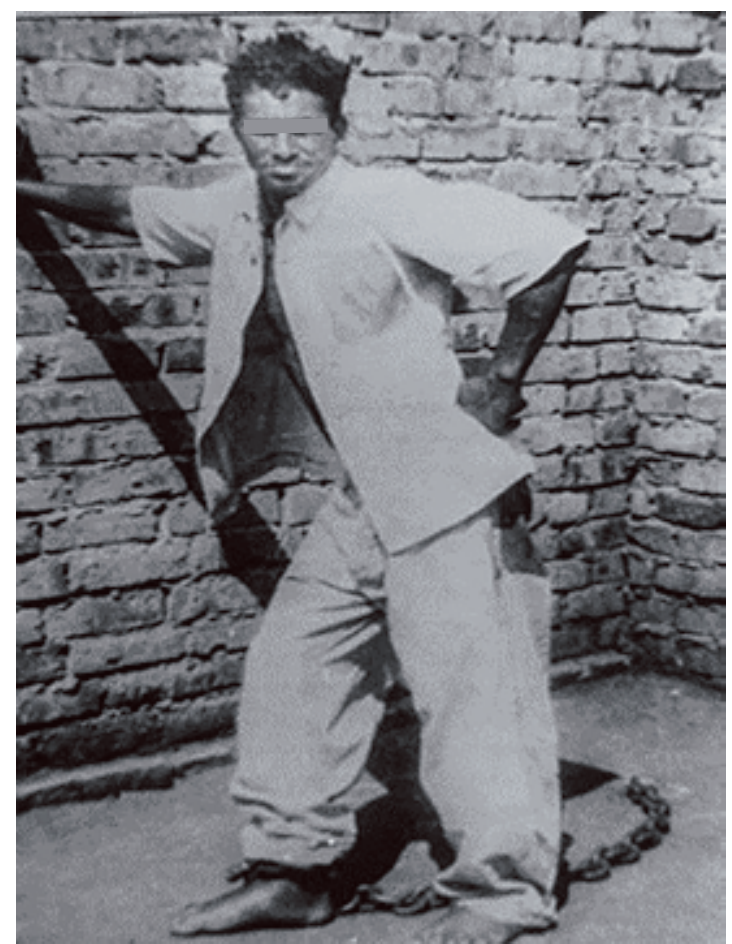


Esta alusión al Bethlem Royal Hospital que funcionó en Londres en el siglo XIV, por antonomasia fue vulgarizado para significar que "se armó un Bedlán", un caos, locura, alboroto, etc., y por ser considerado uno de los mayores espectáculos que abría sus puertas para la curiosidad de los que pagaban por ver las "excentricidades" de los internos, incluso por molestarlos para impresionarse con sus reacciones.

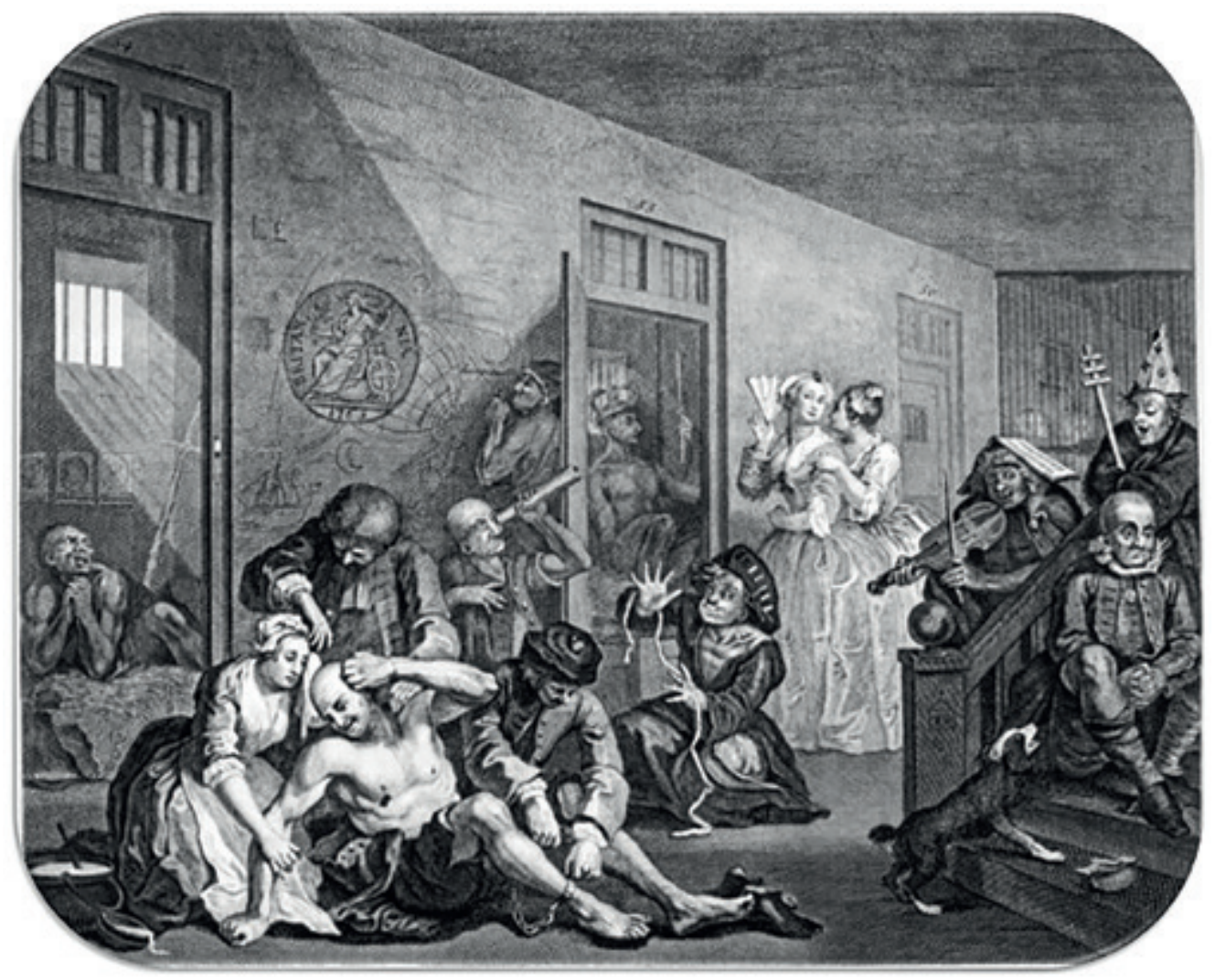

Imagen 11. In The

Madhouse, serie A Rake's Progress, plate 8. William Hogarth, 1734

De igual modo, la Casona de San Isidro en Cali no se libró del exhibicionismo que, según el médico Rómulo Mejía, primer director para 1959, "ni siquiera ha faltado aquella [época] en que los enfermos eran mostrados a trueque de unos pequeños honorarios destinados al sostenimiento de los mismos" (Mejía, 1959, s.f.). Esta disposición la refiere Goffman como un proceso de "mortificación del yo" que deriva de una exhibición contaminadora de tipo físico que, más allá del contacto infecto-contagioso, producía una "humillación" del cuerpo o disciplinamiento para el "buen manejo" médico-administrativo de los asilados (2009, p. 39).

En el siguiente mural (Imagen 12) predomina la entidad femenina de la locura en diversas facetas, como es la mujer obrera, el gesto de la rebelde, la mujer afro, la histérica, la deprimida y la melancólica. La compañía de figuras masculinas son posturas de poder, como la del director del manicomio, el psiquiatra, y el personal de enfermeros. En el centro superior, se representa lo que parece ser una lobotomía, por tratarse de un quirófano y una paciente con la cabeza vendada. 


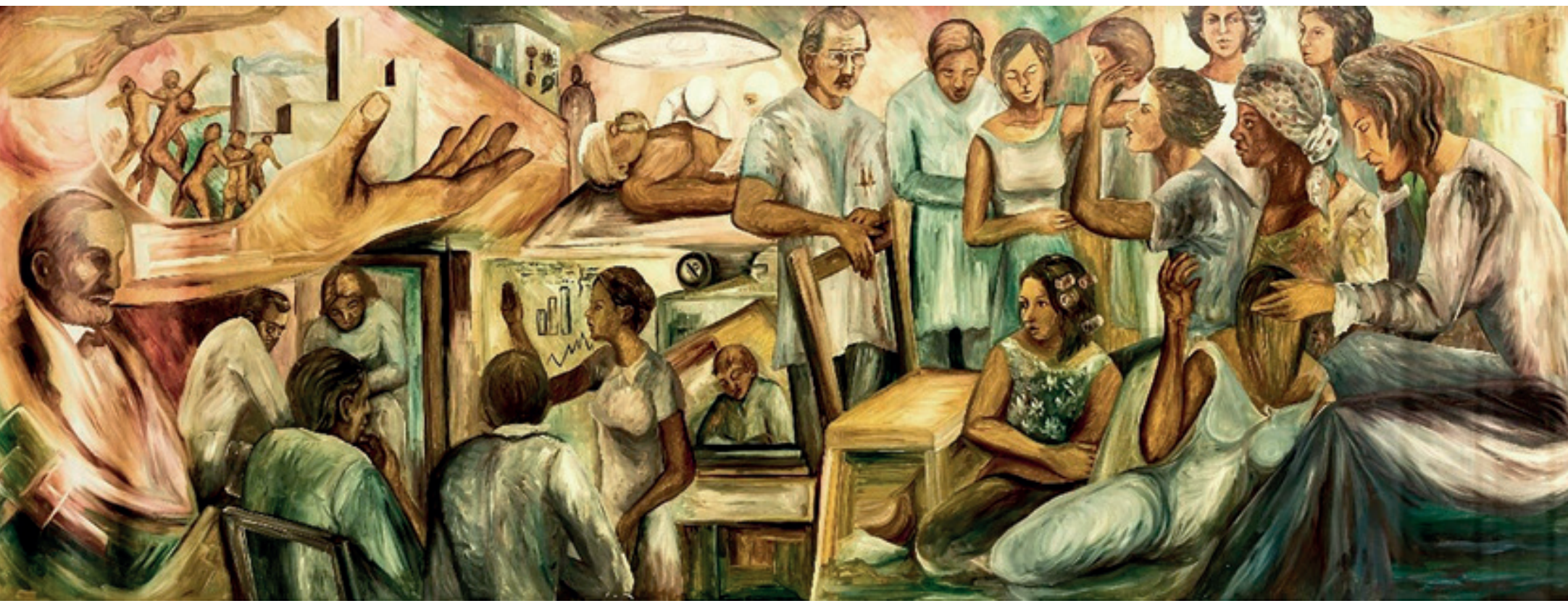

Imagen 12. Serie mural 3 "Pasado y presente de la psiquiatría en Antioquia" Fuente: Antonio Herrera Cardona, 1982. Hospital Mental de Antioquia. Foto: Peláez, R. y Gutiérrez, J. 2013.

Centrado y en lo alto del mural principal (Imagen 2), alza vuelo el alma liberada de las cadenas de la locura, en posición horizontal flotando en el sueño, atraída por una fuerza que la hala del brazo del grillete, estirado hacia arriba y con el cabello suspendido o gravitando en aire. Esta postura es afín con la que flota en la obra de Herrera "Ello, Yo y Super yo", mural de gran formato que también abarca todo el corredor de un pabellón, imagen con la que conviven pacientes, visitantes y personal de salud.

El ascenso del ser se debate en medio de ondas luminosas que parecen una tormenta solar, que alude a la conciencia insondable, sobre las aguas del inconsciente y de la ensoñación. La búsqueda del Yo establece una tensión entre lo estructurado y desestructurado, urbano civilizado y antiguo primitivo, el Súper yo y el Ello. A diferencia de la anterior pose (Imagen 2), en estado de arrojo o flacidez del cuerpo en reposo y el rostro decaído, este otro gesto (Imagen 13) está en movimiento en posición danzarina y el rostro elevado en trascendencia, expresión que inspira fuerza de superación, liberación y despertar de la pesadilla de la oscura noche del alma. 


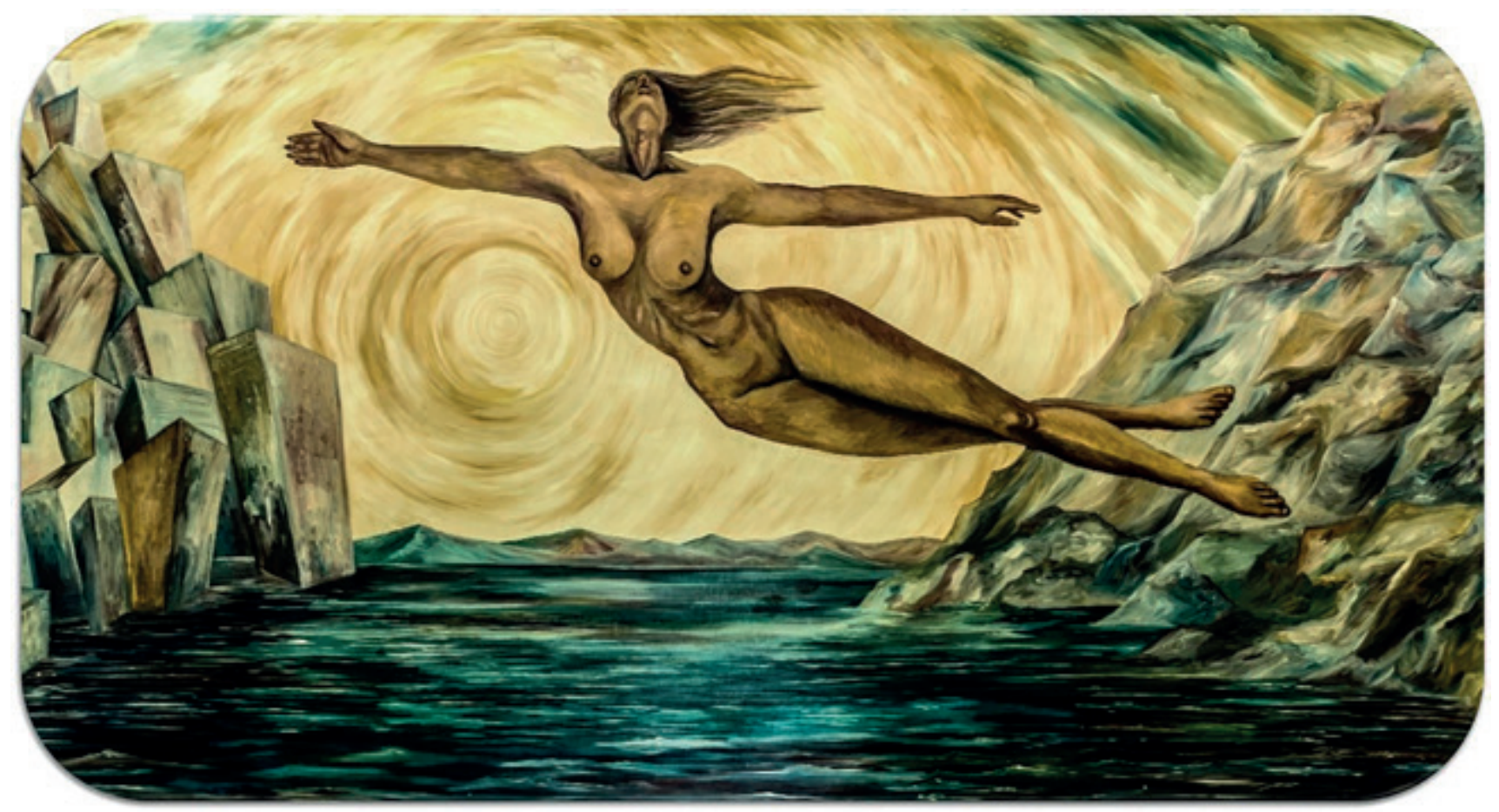

Imagen 13. Mural "Ello, Yo y Súper yo".

Fuente: Antonio Herrera Cardona, 1982. Hospital Mental de Antioquia.

Foto: Peláez, R. y Gutiérrez, J. 2013.

\section{Al final del recorrido}

Un hospital psiquiátrico, más allá de su historia de encierro y exclusión, tiene muros que producen una interioridad llena de experiencias auditivas, táctiles, visuales, entre otras sensorialidades que escapan a la contención. Este recorrido permitió mostrar una visibilidad de lo invisible, en tanto las imágenes constituyen un monumento o fijación de memoria que, en el caso de la locura, desde las pinturas clásicas, se ha plasmado la liberación y la lucha por la dignidad de una población que se consideró deshumanizada, por la pérdida de subjetividad, secuestración y sacrificio del yo, muerte moral, entre otras declaraciones del discurso de la razón y de la mente.

De este modo aparecen motivos y escenas en murales de instituciones psiquiátricas de diversas regiones del mundo, algunos pintados por artistas reconocidos, otros por iniciativa del personal a cargo, como actividad de arte-terapia y laborterapia, incluso por parte de organizaciones sociales con el fin de intervenir el espacio plano, blanco, gris, aséptico, que caracteriza el ambiente hospitalario. 
En este caso, el establecimiento configura una estética arquitectónica, por la representación e imaginación que este espacio crea en la ciudad, así como una poiesis, por las formas simbólicas que comportan los trastornos mentales, expresados en todas las culturas a través del mito, el lenguaje, la religión, la ciencia, el arte y la historia. En este sentido, Carlos A. Uribe, acude a una paráfrasis de Marcel Mauss, en su Ensayo sobre el don, para afirmar que "las enfermedades mentales parecen ser un ejemplo de 'fenómenos totales', caracterizados por una compleja dialéctica que involucra lo biológico, lo psicológico y lo sociocultural, todo dentro de un tejido de representaciones culturales sobre el cuerpo, la subjetividad, el género, la enfermedad, la experiencia y, en general, la realidad" (2000, pp. 345-366).

Según Juan B. Londoño, director del Manicomio entre 1914 y 1917 y primer catedrático de psiquiatría en Antioquia, "partimos del principio de que el loco es, entre todos los desheredados, el sér á quienes las sociedades... deben ver con más consideraciones, y de que una casa de locos es algo así como el reflejo de la cultura intelectual y moral de los pueblos" (1897, p. 204). De manera semejante, seis décadas más tarde, Foucault afirmaría que "una historia de la locura sería una historia del Otro - de lo que para una cultura es, a la vez, interior y extraño y debe por ello excluirse (para conjurar un peligro interior), pero encerrándolo (para reducir la alteridad)" (1989, p. 9); de ahí que, conocer el trato que se procura a los otros, los excluidos por fuera de la norma social, jurídica y moral, es una forma de develar la concepción de humanidad que tiene una sociedad.

\section{Referencias}

Aljure, F. (1955). Informe del Presidente de la Junta Directiva del Asilo San Isidro, dirigido al Director Departamental de Higiene, octubre 25, Archivo Histórico del Hospital Psiquiátrico Universitario del Valle. En: Gutiérrez, J. (2015). Caracterización sociodemográfica, psicopatológica y terapéutica en la primera década de servicio del Hospital Psiquiátrico San Isidro del Valle del Cauca, 1958-1968. Revista Colombiana de Psiquiatría, 44, julio-septiembre, pp. 14-21.

Didi-Huberman, G. (2007). La invención de la histeria. Charcot y la iconografía fotográfica de La Salpêtrière. Madrid: Cátedra.

Castro, A. (1920). Degeneración colombiana. Medellín: Lit. e Imp. J.L. Arango, 1920.

Foucault, M. (1989). Las palabras y las cosas: una arqueología de las ciencias humanas. Buenos Aires: Siglo XXI.

Goffman, E. (2009). Internados, Ensayos sobre la situación social de los enfermos mentales, Buenos Aires: Amorrortu.

Gómez, J. (2005). Psicopatología de la expresión. Titulado Universitario Senior, Universitat Jaume I.

Disponible en: http://mayores.uji.es/proyectos/proyectos2005/psicopatologiadexpres.pdf

Gutiérrez, J. y Márquez, J. (2014). Pobreza y locura como enfermedades sociales en la mentalidad civilizadora de la modernidad colombiana, 1850 - 1960. Revista Facultad Nacional de Salud Pública, 4(32), octubre-diciembre, pp. 56-66.

Gutiérrez J. y Márquez, J. (2017). Degeneración, delirios y nervios: Etiología en la primera psiquiatría 1893-1912. En: Restrepo, E., Gutiérrez, J. (2015). Del régimen asistencialista a la psiquiatría dinámica en las primeras instituciones de salud mental en Cundinamarca, Antioquia y Valle del Cauca, 1900-1968. En: Casas, A. y Congote, J. (2015). Actualizando discursos. Trazos de historia de la psiquiatría y de la salud pública en el contexto iberoamericano. Medellín: UdeA - L.Vieco. 
Sánchez, C. y Silva G. (2017). Ciencias de la vida. Colección del Sesquicentenario. Bogotá: Universidad Nacional de Colombia Jiménez, M. (1920). Nuestras razas decaen. Algunos signos de degeneración colectiva en Colombia y en los países similares. Memoria presentada al Tercer Congreso Médico Colombiano reunido en Cartagena en enero de 1918. Bogotá: Imprenta y Litografía de Juan Casis.

Hernández, A. (2000). De la pintura psicopatológica al arte como terapia en España (1917-1986). Tesis de Doctorado en Nuevos Medios y Narratividad Audiovisual, Facultad de Bellas Artes, Universitat Politècnica de València. doi:10.4995/Thesis/10251/5846.

Lopera, J.D. (2016). Sabiduría práctica y salud psíquica. Bogotá: Editorial San Pablo - Fondo Editorial Universidad Eafit, 2016.

Londoño, J.B. (1897). Manicomio Departamental. Anales de la Academia de Medicina de Medellín, 8 (6-7), p. 204.

Mejía, R. (1959). La asistencia psiquiátrica en el Valle del Cauca, VI Congreso Médico Nacional, Bogotá, julio. Archivo Histórico del Hospital Psiquiátrico Universitario del Valle, Cali.

Montilla, J. (2016). Enajenadas. Ilustraciones médicas de la locura femenina en el siglo XIX. Madrid: Brumaria.

Museo Casona de San Isidro (2013). Hospital Psiquiátrico Universitario del Valle del Cauca, Cali.

Perdomo, R. (1996). Premio Vida y Obra al servicio de la Psiquiatría otorgado a Carlos A. León. Revista Colombiana de Psiquiatría, 25(4), pp. 298-301.

Putnam, C.E. (1913). Informe presentado a la Academia Nacional de Medicina. Revista Médica de Bogotá, 31, septiembre, pp. 248259.

Restrepo, M. (14 de noviembre, 1978). Todo es posible... menos volar. Hospital Mental de Antioquia (III). El Colombiano, p. 12A.

Robledo, E. (1920) ¿Existe una degeneración colectiva en Colombia? Medellín: Tipografía Industrial.

Rosselli, H. (1968). Historia de la psiquiatría en Colombia (2 tomos). Bogotá: Horizontes.

Simmel, G. (2011). El individuo y la libertad. Ensayos de crítica de la cultura. Barcelona: Península.

Uribe, C. (2000). La controversia por la cultura en el DSM-IV. Revista Colombiana de Psiquiatría, 29 (4), pp. 345-366.

Uribe, L. (1923). Principales factores etiológicos de la locura en los departamentos de Antioquia y Caldas. Revista clínica: órgano de la Sociedad clínica del Hospital de Medellín, 03 (25-28), noviembre, pp. 188-198. 